The spectra of double molecule chains give, as one would expect, strong odd orders and weak even, whilst the single chains give orders decreasing uniformly in intensity.

Mr. S. H. Piper gave some examples of the use of $\mathrm{X}$-ray spectra in distinguishing between long chain compounds of similar types. It was possible to show that the fractions obtained by distilling paraffin wax in vacuo were not identical with normal hydrocarbons. For example, one fraction having the same number of carbon atoms in the chain as dotriacontane showed a very much smaller spacing. All fractions appeared to photograph as pure substances, and it was interesting to notice that the lines shown by a film of crude paraffin wax melted on glass gave the same spacing as one of the eight fractions. On mixing this fraction with one or more of the others, its lines only appeared on the plate.

Dr. Müller mentioned that the main spacing given by certain hydrocarbons appeared to have two possible values, indicating two possible crystalline structures for these substances.

Mr. W. T. Astbury indicated how it is possible to determine from X-ray measurements, by making use of the theory of space groups, the elements of symmetry possible to the molecules in the crystal cell. It is then possible to distinguish between two or more structural formulæ for a given compound. A most valuable series of tables was shown giving the possible molecular symmetry for all the 230 space groups.

\title{
Oyster Mortality in I920.
}

PART I. of the report under notice ${ }^{1}$ was reviewed in NATURE of July Io, p. 82. It contained Dr. Orton's Final Report, while Part II. commences with his Interim Report of December 30, 1920, which apparently is now published for the first time. It shows the preliminary biological investigations that were made by Dr. Orton, together with his examination of the dumping-ground for explosives in the Black Deep, and is altogether admirable. Why this was not printed in proper sequence, these being the preliminary conclusions of the same author, it is impossible to understand. Further, if it had been published as soon as received instead of in 1924, it would have relieved the minds of those concerned with the oyster industry, and probably elicited from them much further information, besides stimulating and directing their own observations ; those responsible for the industry are not unheeding of the results of scientific research.

Dr. Orton's interim report is followed by a series of valuable research reports on special questions. Dr. Eyre's very thorough investigations, mainly shown in tables, lead to the conclusion that no evidence points to the excessive mortality being due to disease of bacterial origin. Dr. Brady tested very thoroughly from the chemical side and came to a similar negative conclusion in respect to the dumped munitions of war. The Government Chemist and his staff in four reports are largely concerned with arsenic, which is very widely contained in silts formed from rocks containing arsenic. As diseased

1 Ministry of Agriculture and Fisheries. Fisheries Investigations, Series 2, vol. 6 , No. 4, 1924: An Account of Investigations into the Cause or Causes of the Unusual Mortality among Oysters in English Oyster Beds during 1920 and I92I. Part 2: Chemical Reports, (r) by George Stubbs, Andrew More and John Ralph Nicholls, and (2) by Dr. O. L. Brady Bacteriological Reports, by Prof. J. Eyre; Report on Field Work, by F. S. Wright ; Biological Investigations, by Dr. J. H. Orton; Recommendations as to Further Research, by Dr. J. H. Orton. Pp. 69. '(London H.M. Stationery Office, I924.) $7 s .6 \dot{d}$. net. and healthy oysters have the same amount, this clearly cannot account for the mortality, nor is there any suggestion of the mortality possibly being due to "dumping" of arsenic compounds either by factories or by the Munitions Department. However, the possibility of arsenic in oysters being of danger to man is unavoidably raised, especially as the silts of the Fal contain large quantities of copper, zinc and tin also, whereas these are practically absent from the oyster grounds of the Thames estuary and the East coast. The present reports, critically examined in connexion with former researches, give no cause for any suggestion of danger to human life from these substances as consumed by the most gluttonous lover of oysters. Yet, we do not think these researches should stop here without a more definite examination and pronouncement on this question by the Government Chemist, whose staff must now have considerable experience in the necessary analyses, and who can consult as may be advisable with the expert physiologists of the Ministry of Health.

If the analyses of any oysters give any suggestions of danger, the beds from which those oysters come must clearly be closed for direct sales, the fish being first laid elsewhere for a period sufficient to remove the noxious substance, as is required for bacterial infections. What is first required, however, is a definite proriouncement as to what constitutes danger. Without this the present report will inevitably give rise to alarm, if it ever becomes known to the " man in the street." This is unlikely, however, as it costs 7s. $6 d$. for 69 pages, without illustrations, and free copies are not distributed. This is scarcely the way in which to make scientific research popular. Our Government authorities have much to learn from a study of the effect of a liberal free distribution of similar reports in the United States. J. S. G.

\section{The Thermal Efficiency of Steam Engines.}

A

DISCUSSION on the standards of comparison in connexion with the thermal efficiency of steam engines was held at the Institution of Civil Engineers on Thursday, December II. The Heat Engine and Boiler Trials Tabulation Committee has appreciated the fact that the present standard of comparison needed development, and asked Capt. H. Riall Sankey to prepare a memorandum on the subject with a view to discussion at a joint meeting of the Institutions represented on the Committee (v. Nature, December 6, p. 835). The I896 Committee of the Institution of Civil Engineers, under the chairmanship of Sir Alexander Kennedy, proposed the Rankine cycle as a standard. Since that time the practice of heating the feed-water by live steam abstracted from the engine during expansion, known as "bleeding," has been developed, resulting in considerable economy, but to this case the Rankine cycle does not apply. The practice is also adopted of reheating the steam after a partial expansion, a process which can be repeated once or more, after which the steam is expanded to the back pressure, but it would be stretching the definition of the Rankine cycle to apply it to this case. Further, these feed-heating and reheating cycles can be combined, and the question arises, can a standard of comparison be defined that will meet all cases? 
It is submitted that the following extended definition can be applied to all cases:

It is assumed that all the component parts of the steam plant are perfect, and that there are no losses due to initial condensation, leakage, radiation, or conduction, and that there is no clearance in the cylinder. The feed-water required is taken into the boiler at the exhaust temperature, and its temperature is gradually raised until that corresponding to saturated steam is reached. Steam is then formed at constant pressure until dry saturated steam is produced, after which, if the steam is to be superheated, heat is added at constant pressure and at increasing temperature, until the required temperature of superheat is reached. The steam is introduced into the cylinder at constant pressure, displacing the piston, and performing external work equal to the absolute pressure multiplied by the volume swept through by the piston up to the point of cut-off. Beyond that point expansion takes place adiabatically, doing work until any desired pressure is reached, when the steam is reheated at constant pressure to any desired temperature whence adiabatic expansion takes place; such reheating process can be repeated as often as desired. Finally, the steam is expanded adiabatically until the temperature of saturation corresponding to the boiler pressure is met. From this point, either adiabatic expansion continues doing work until the pressure in the cylinder is equal to the back pressure against which the engine is working, or the steam is expanded so that a portion of the heat is transferred to the feed-water in such a manner that at every temperature the amount of heat so transferred is equal to the increase in water-heat at that temperature, until the pressure in the cylinder is equal to the back pressure against which the engine is working. The steam is then completely exhausted from the cylinder at constant pressure corresponding with the lower limit of temperature, work being done on the steam by the engine during exhaust, equal to the absolute back pressure multiplied by the total volume swept through by the piston. The steam is thus removed from the cylinder and the cycle is complete.

In practice, the following main cases occur resulting from the omission of one or more of the factors of the comprehensive definition :

(I) Saturated steam with simple adiabatic expansion to the back pressure.

(2) Superheated steam with simple adiabatic expansion to the back pressure.

(3) Superheated steam with one or more reheats with final adiabatic expansion to the back pressure.

(4) Saturated or superheated steam with feedheating expansion to the back pressure.

(5) Superheated steam with one or more reheats, and final feed-heating expansion to the back pressure.

The thermal efficiency of any heat engine is defined as the ratio of the heat utilised as work to the heat supplied. Capt. Sankey gives some worked-cut examples to illustrate the method, and makes use of the Mollier chart and of Callendar's Fahrenheit Steam Tables. He also includes tables of results of a large number of other calculations for different cases, and includes among these one illustrating the Benson cycle, in which steam is generated at the critical temperature $\left(706^{\circ} \mathrm{F}\right.$.) at a pressure of $3200 \mathrm{lb}$. per sq. inch absolute. For comparison, the thermal efficiencies of a gas engine and of an oil engine have also been worked out and are included in the tables.

Capt. Sankey's memorandum gives some idea of the arduous task which the Committee has had to face, and the final recommendations will be welcomed by the engineering profession.

\section{Parker Plant for Low Temperature Carbonisation.}

TTENTION has already been directed in NATURE A (September 20, p. 44I) to the Government offer to test at public expense approved processes for the carbonisation of coal at low temperatures. The Low Temperature Carbonisation Company, Ltd., has been quick to submit for test the standard unit of "Parker" plant installed near Barnsley at Barugh (locally pronounced " bark," it may be added for the enlightenment of the uninitiated). The Department of Scientific and Industrial Research has now issued a report of the test made in July last. The Director of Fuel Research in a prefatory note emphasises that the report is on technical results only, and that " no attempt is made to pronounce on the commercial possibilities of the plant."

The coal is carbonised in vertical iron tubular retorts, $9 \mathrm{ft}$. long and of average diameter of $5 \mathrm{in}$., the retorts being cast in groups of 12 assembled in a setting of 32 groups. The setting is heated by the gas made, and is equipped with closed chambers below the retorts to receive the coke after carbonisation, and allow it to cool without quenching and consequent contamination with moisture. Such a setting was designed to have a throughput of 50 tons of coal per day, and in the test, lasting two days, it was found that this claim was substantiated.

The coal employed was " Dalton Main," with which the Fuel Research Station had already considerable experience. It was a washed slack, fairly dry, containing 5 per cent. only of ash-a low figure for commercial supplies of coal. The yields of products per ton of coal as charged were :

Coke . . . $13.92 \mathrm{cwt}$.

Gas . . . 5620 cub. ft. or 39.6 therms.

NO. $2 \$ 77$, vOL. I I 4$]$

\section{Tar . . . I8.62 gallons.}

Crude Spirit (motor) . I·78 gall. yielding I $\cdot 39$ gall. of refined product.

Liquor . . . . 26 gall., equivalent to $13.55 \mathrm{lb}$. of ammonium sulphate.

The coke produced, the report states, was of suitable size, not friable, contained little breeze, and only 4 per cent. of volatile matter. It successfully withstood an eight-day railway journey to the Fuel Research Station, was readily ignited in a household grate, and gave a good hot fire. It would appear, therefore, that the claim that the process produced a smokeless domestic fuel was substantiated. The analysis showing a volatile content of some 4 per cent. raises a doubt as to whether this fuel will develop the " cheerful blaze" which is so attractive to lovers of a coal fire, and contributes so much to speed of ignition.

The yield of tar was high, and chemically it was of the "low temperature " character. The yield of crude motor spirit was moderate, but the refining loss and consequent cost was considerable. The quantity of ammonia recovered per ton was good for low temperature practice, though low judged by existing carbonising practice, while the liquor obtained was so dilute that it is considered doubtful whether recovery was commercially justifiable.

The whole of the rich gas made was employed in heating the setting, supplemented by some producer gas specially generated. Compared with modern carbonising practice, this is a high fuel consumption, and it is pointed out in the report that a reduction could be effected by better design of the plant. The loss of this rich gas is more serious commercially, as the gas is the most valuable and least speculative 